\title{
The Independent and Interdependent Self-affirmations in Action: Understanding their dynamics in India during COVID-19
}

\author{
Ruchi Pandey ${ }^{1}$, Gyanesh Kumar Tiwari ${ }^{1}$, and Pramod Kumar Rai ${ }^{1}$ \\ ${ }^{1}$ Department of Psychology, School of Humanities \& Social Sciences, Doctor Harisingh \\ Gour Vishwavidyalaya, Sagar, 470003, Madhya Pradesh, India
}

May 15, 2020

\begin{abstract}
The study explored the role of two dissimilar familial and religious practices in distinctly shaping independent and interdependent self-affirmations in two value systems surfaced to protect self-integrity and self-worth challenged by the threats of COVID-19. A qualitative method was employed which recruited a heterogeneous sample of 19 participants (10 joint and 9 nuclear families) who reported the consequences of COVID-19 and the roles of familial and religious values in facing the pandemic threats through a semi-structured interview. Five themes were generated: the perceived strong threat of COVID-19, positive roles of joint familial values and the religious values, dissimilar roles of individualistic and collectivistic values as well as traditional and modern religious values. Threats were expressed in the experiences of anxiety, uncertainty and mood fluctuations. Interdependence, affiliation and support were joint familial values whereas worshipping, divine interpretation and spiritual practices denoted traditional religious values. Independence, scientific interpretations and personal focus were individualistic family values. Focus on explicit attributes denoted modern while divine interpretation, will of God and dependency on God reflected traditional religious values. Coexistence of independent and interdependent self-affirmations originating from two distinct familial and religious value systems was observed possibly due to the current transitions in the Indian society.
\end{abstract}

\section{Keywords}

COVID-19; Indian family; narrative thematic analysis; pandemic; religious and familial practices; self-affirmation; social practices; threat.

\section{Introduction}

The pandemic COVID-19 has left not even a single person untouched from its direct or indirect negative consequences. COVID-19 is a highly infectious leading to severe respiratory disease with the symptoms of cough, breathing problems, fever, chills, repeated shaking with chills, muscle pain, headache, sore throat and new loss of taste or smell (Centers for Disease Control and Prevention, 2020; World Health Organization, 2020a). Its severity can be understood in terms of the number of people it has inflicted in a very short period. It has been reported that there were 3, 018, 681 confirmed and 207, 973 death cases due to the infection of COVID-19 as on April 30, 2020 (World Health Organization, 2020).

Unlike previous epidemics, COVID-19 is very fatal, unknown and unexpected. It has been argued that an epidemic gives rise to parallel complex social and psychological processes which become an epidemic in itself (Strong, 1990). These psycho-social epidemics lead to fear and explanation and may culminate in distrust, uncertainty, ridiculousness, propaganda, terror, social stigma, avoidance, separation, exploitation and multiple theories of the origin of disease and misconceptions among people (Strong, 1990; Weber \& Goldmeier, 1983). These factors may lead to many social, psychological, economic and health ill-consequences for people of all age groups and origins (United Nations Organization, 2020). Recent studies 
have reported many negative psychological and other life outcomes due to COVID-19. For example, the researchers have reported that the current pandemic causes extreme stress, anger, restrictions and fear of infection (Brooks et al., 2020) and panic experiences, feeling of isolation, anxiety, irritability, lowered social support and a variety of negative health outcomes for children and adults (Jiao et al., 2020; Tiwari et al., 2020).

The universal severe threat caused by COVID-19 may be argued to pose serious challenges to the self-integrity and self-worth of people due. People use a variety of psychological mechanisms to protect their self-integrity and self-worth and self-affirmation has been suggested as one of the positive mechanisms people use to protect them and face challenges of life (Steele, 1988). Self-affirmation refers to a set of motivational processes that help people to regain their self-integrity and self-worth in the face of threats (David K. Sherman \& Cohen, 2006; Steele, 1988). Self-integrity and self-worth are socially shared conceptions and originate from socio-cultural and historical processes (Alexander, 2014) and suggested to be helpful for people for its unique ability to cultivate cognitive flexibility (Geoffrey L. Cohen et al., 2007), positive social comparisons in times of failure (Pettit \& Lount, 2010), collective identity (Binning et al., 2010), reduction of prejudice (David K. Sherman \& Kim, 2005), positive health outcomes (David K. Sherman et al., 2000) on the one hand and to lower negative psychological and physiological outcomes on the other (J. D. Creswell et al., 2005). These benefits may be more valid for people brought up in individualistic culture who carry independent self as it may differ in the basic structure and dynamics from interdependent self (Cai et al., 2013). Independent selfconstrual represents a focus on the protection of individual rights and cognitions. Conversely, interdependent or relational self-construal features connection, relation and wide social units (Markus \& Kitayama, 1991). Thus, the benefits of independent self-affirmation may not be directly generalized to the individual having interdependent self-construal (Cai et al., 2013).

The relational self may comprise familial self and close-other self and its defensiveness-soothing caused by relational self-affirmation effects may occur due to the familial bonds (Heine \& Lehman, 1997; HoshinoBrowne et al., 2005). Relational self-affirmation may be more useful for people of Indian society which is collectivistic in nature. Relational self-affirmation may be more guided by interdependence, affiliation and social harmony (Hoshino-Browne et al., 2005). The major precursor of relational self is the unique familial value which is orientated towards relationships and others' concerns (Gaines et al., 1997). Familialism has been conceptualized as a cultural value involving interdependent, emotional and relatively permanent relationships (Cai et al., 2013). Familial bonds may comprise groupness, shared identity, deep attachments and unique socialization, emotionality and meaning (Scabini \& Manzi, 2010). Researchers have argued that these basic differences in two types of self-construal may have significant implications for affirmation processes (Cai et al., 2013; Hoshino-Browne et al., 2005; Tiwari et al., 2020).

The Indian value system is characterized by collectivism, conformity to norms, deference to authority, emotional self-control, achieving for family recognition, humbleness, hierarchical nature of relationships and avoidance of shame and these values help in developing a positive self-concept (Iwamoto \& Liu, 2010; Kim et al., 1999; Kim \& Omizo, 2005). Likewise, attitudes, values and perceptions are shaped according to the nature of socialization practices (Helms \& Cook, 1999). Indian joint family is a unique institution which has been suggested to cultivate a set of collective values that may shape the self-affirmation process distinct from a nuclear family prominent in individualistic societies. Interdependent self-construal and collective values cultivated by the Indian joint family may prompt the affirmation process in Indian people in the face of pandemic threat through a positive feedback loop between the self-system and the social system (G. L. Cohen \& Sherman, 2014) and may have motivated them to follow the desirable restrictions leading to the mass support instead of opposition (Tiwari et al., 2020).

Religiousness denotes beliefs, practices and experiences linked with organized traditions (Cheadle \& Dunkel Schetter, 2017) which also include spirituality (Harris et al., 2018). Hindu religion is one of the oldest religions and its present form has been evolved from a long assimilation process. Worshipping idols of God and Goddess, reading religious texts and carrying out hawan and pooja (a kind of sacrifice) is most popular in India. It is said that Hinduism is not a single religion but a way of life that provides for the doctrines 
of samsara (purification) and karma (the universal law of cause and effect), soul, moksha (salvation) and dharma (a code of living) (History.com Editors, 2019). These core features have significant influences on the social behaviours of the majority of the Indians (History.com Editors, 2019). In a recent study, core values of religion have been found to facilitate self-affirmation by augmenting self-integrity and self-worth resulting in enhanced adherence to clinical prescriptions (Bormann et al., 2013; Kemppainen et al., 2012; Smith, 2019). Moreover, there is little consensus of the origin and mechanisms inherent in self-affirmation shaping life outcomes (Alexander, 2014). The current study aims to explore the role of familial and religious practices in easing independent and interdependent self-affirmations in the relevant values in facing the threat of COVID-19 in a heterogeneous sample by employing the Narrative Thematic Analysis Method (J. W. Creswell, 2014). The use of qualitative methods has been suggested to be useful where there is no guiding framework or theory to explore a phenomenon (J. W. Creswell, 2004, 2014). Besides, it was not possible to collect data on a large sample through quantitative measures due to the strict nationwide lockdown in India.

\section{Methods}

Nineteen participants (Age Range $=25-43$ years, Mean Age $=33.63, \mathrm{SD}=508$ ) were chosen through a purposive sampling method take part in a qualitative study. Out of these, 10 were from the joint families (Age Range $=25-43$ Years, Mean Age $=34.50, \mathrm{SD}=5.23)$ and 9 were from the nuclear families $(\mathrm{N}$ $=9$, Age Range $=27-41$ Years, Mean Age $=332.67, \mathrm{SD}=5.03)$. The participants belonged to [BLINDED FOR REVIEW]. The detailed demographic information has been displayed in Table 1.

Table 1. Biographic information of the participants

\begin{tabular}{|c|c|c|c|c|c|c|c|}
\hline S. No. & Age & Gender & Family & Family Size & Domicile & Education & $\begin{array}{l}\text { Marital } \\
\text { Status }\end{array}$ \\
\hline 1. & 33 & Male & Nuclear & 3 & Urban & Postgraduation & n Unmarried \\
\hline 2. & 30 & Female & Nuclear & 3 & Urban & Postgraduation & n Married \\
\hline 3. & 30 & Female & Nuclear & 3 & Urban & M. Phil & Unmarried \\
\hline 4. & 34 & Female & Joint & 7 & Urban & Postgraduation & n Married \\
\hline 5. & 30 & Male & Joint & 7 & Urban & Postgraduation & n Married \\
\hline 6. & 29 & Female & Nuclear & 3 & Urban & Postgraduation & n Married \\
\hline 7. & 27 & Male & Nuclear & 5 & Rural & Graduation & Unmarried \\
\hline 8. & 25 & Male & Joint & 6 & Urban & Graduation & Unmarried \\
\hline 9. & 30 & Female & Joint & 6 & Rural & Ph.D. & Unmarried \\
\hline 10. & 29 & Female & Nuclear & 4 & Urban & Postgraduation & n Unmarried \\
\hline 11. & 33 & Male & Joint & 9 & Rural & Postgraduation & n Married \\
\hline 12. & 35 & Male & Nuclear & 4 & Urban & Postgraduation & n Unmarried \\
\hline 13. & 38 & Female & Joint & 8 & Rural & Graduation & Married \\
\hline 14. & 39 & Male & Joint & 8 & Urban & Graduation & Married \\
\hline 15. & 40 & Male & Nuclear & 4 & Rural & Ph.D. & Unmarried \\
\hline 16. & 41 & Female & Nuclear & 3 & Urban & Graduation & Married \\
\hline 17. & 43 & Male & Joint & 9 & Rural & Postgraduation & n Unmarried \\
\hline 18. & 37 & Male & Joint & 8 & Urban & Graduation & Married \\
\hline 19. & 36 & Female & Joint & 10 & Urban & Graduation & Married \\
\hline
\end{tabular}




\section{Research Design}

A telephonic semi-structured interview protocol for data collection was used that employed the Narrative Thematic Analysis method for data analysis (J. W. Creswell, 2014), a constructivist approach of inquiry to develop a deeper understanding and exploration.

\section{Research Team, Contributions, Extraction and Participant Recruitment}

All three authors have a good background in qualitative research in Psychology. The first author was a doctoral candidate while the rest two were faculty members. The differences in age and experiences were managed by frequent discussion. Authors 1 and 2 helped in conceptualization, data collection, analysis and manuscript writing while authors 3 helped in analysis and manuscript writing. Out of 29 initially contacted, 20 participants gave their consent and the rest did not participate. The participants were known to the researchers before the study, and no compensation was paid. The study was approved by Institutional Ethics Committee approval. The consent was ascertained on the telephone. A convenience sampling method was used. The sample size was determined as per the suggestions of Guest et al. (2006). The participants were debriefed as per the objectives. The saturation was determined after completion of 16 interviews when no new codes relevant to the research questions generated (Saunders et al., 2018). The interview protocol was evolved with the help of discussion among the researchers.

\section{Data Collection}

Data from each participant were collected through telephonic contact during the stay at their home during the lockdown. The interviews were held from 36 to 43 minutes with an average length of 40.20 minutes. Nature, severity and impacts of the pandemic on your life and the roles of the familial and religious values helpful in coping with the threat of COVID-19 were the basic questions. The contents were recorded in writing while conducting the interviews.

\section{Data Analysis}

The Narrative Thematic Method was used (J. W. Creswell, 2014). This method contains the organization and preparation, a general sense of the information, coding, generating categories or themes and interpreting the data (J. W. Creswell, 2014). Confidentiality and reliability were ascertained through the assignment of code to each participant and checking/rechecking of the codes. The reading and rereading of the transcriptions enhanced familiarity with the meanings and insights from the data (Barbour, 2001). To keep a record of the codes, a handwritten codebook was made. An iterative approach helped to enhance the quality of coding. A gap of two days was observed the scrutiny and reviewing of the transcripts to lower the distortions caused by over-involvement (Guest et al., 2012). The methodological integrity was increased by the evaluation of the data adequacy, analysis approach, frequent discussion, attending the evidence and a goals-focused consistent analysis.

\section{Results}

Five themes were generated regarding the familial and religious roots of independent and interdependent self-affirmations.

\section{Theme 1: COVID caused a strong threat among the participants.}

Participants expressed their threat in many ways. Their threat was expressed in their reported anxiety, pain, panic experiences, helplessness and fluctuations in moods: 
Due to COVID-19, I often experience anxiety and depression, I am really worried about future; I don't know when this lockdown will get over when we will live like we used to do; I am stuck in my house and living at the same place since last thirty days has made me impatient, I cannot go out, cannot meet friends, family, people, relatives, I am just bored, there is nothing to do as such. (M_1)

Few of the participants said that they are very cautious all the time:

I've to think in advance about grocery and daily used items of home, the period is very uncertain, I've to remain alert all the time that's a change in my behaviour. (M_1) While buying groceries and vegetables many times I've to think about others, I started restraining my requirements so as others who are in more need can be benefitted. (F_2)

Different kinds of concerns are raising difficulty in coping:

We don't have ample space in our house, and seven members are there in my family, this lockdown has made our life hell, usually, members live in different cities, so earlier we didn't have much problem of space, now as all of us are young adults so it makes a real challenge for us. (M_5)

There are very limited options for treasure, relish, that makes me upset. I am tired of watching television and fed up of the news on COVID-19. (M_8)

\section{Theme 2: Values of the joint family played a direct and positive role in affirma- tion leading to perceived positive outcomes.}

Many participants expressed the importance of the joint family in their life:

I am fortunate to have family in this critical time of life, I couldn't imagine my life without them; at least, I've got some people to bang on, to have a chit chat, to play, to tease, it is the only thing that is helping me to be functional in this critical period. (M_11)

I hardly remember when I had last spent time with my family, now I can say I was unlucky but at present being present with parents and other siblings make me feel lighter and happier. ( $\left.\mathrm{F}_{-} 10\right)$

Some expressed that their family is strengthening their abilities:

My father has helped me in overcoming anxiety, he's so calm, he made me realise the important aspects of my life that led me to focus and work on those fronts, I didn't know that I was good in tall those stuff, his trust played a great role, I am grateful to him and I really believe that joint family is a kind of a blessing in one's life and I've experienced it personally during this COVID-19, otherwise, we usually stay far away from parents. God knows what would have happened if I had to live alone and stuck in COVID-19 situation far away from my family, I cannot even imagine. It's horrible to even think off. (F_9)

\section{Theme 3: Religious values have an explicit role in affirming values.}

Many participants expressed that they were observing peace in their life due to religious practices:

Although I used to worship God regularly, I never found that kind of peace which I am observing these days; it gives a feeling of completeness, I've started enjoying it, earlier it was an act or ritual to perform on daily basis, but now I am experiencing some difference. (F_2)

Bhakti gives me immense pleasure and makes me temporarily forget about my problems and simultaneously gives me the required positivity in life to deal with the problems. (F_6)

Participants said that they are worshipping many times a day, they are engaging in religious acts of praying and sadhana (meditation). 
I wake up at 5 am and perform puja (worship) and sadhana and after that, I start my day. It gives me a good feeling all day. It helps me in remaining calm during this stressful period all over the world. (F_4)

\section{Theme 4: Individualistic and collectivistic family values were observed in dis- similar roles for affirmation.}

Participants residing in the joint family have different expressions than with those residing in nuclear family:

For me, a family has not much role to play in my life even during this crisis, its only me who is going to help me in the long run. (M_1)

I have started cooking and that makes me feel good, I've tried different food recipes and got the chance to learn from my mother. This is the way I am engaged and spending time with my family. $\left(F_{-} \_10\right)$

I am spending quality time with my family, which I frequently used to crave for, now almighty has allowed me to enjoy this precious time with my family. (F_3)

\section{Theme 5: Traditional and modern religious beliefs and practices were observed with dissimilar implications for affirmation.}

Some of the participants expressed spiritual inclination rather than religious values:

I hardly found that worshipping God will result in something; I prefer meditation hence on regular basis I engage in it. I practice 30 minutes of meditation every day and now trying to increase my mediation duration. I have seen that mediation is helpful and it helps in overcoming my anxiety. (F_3)

I have started reading "Ramayana, Mahabharat" and other good literature and find it useful in today's critical situation. It helps me in connecting with my roots. (M_5)

Few others expressed that Yoga is helpful during this crisis and for them, this is the way of engaging into religious worship:

I experience immense happiness and satisfaction whenever I do Yoga, earlier I used to do only few Yoga Asanas like "Surya Namaskar, Anulom Vilom, Kapalbhati" but now am performing several other yoga asanas; this has made me more competent and contented. (M_7)

\section{Discussion}

The findings showed that the outbreak of COVID-19 has created a strong and unusual threat to the life of the participants, their family members and community. The threat was perceived as very severe and imposed a demand to activate values capable of protecting well-being and self-integrity. The usual personal values did not seem to work and, thus the participants lend support from familial and religious values with which they were well-familiar and apt. These values were well-known and admired in Indian society for long. The participants from nuclear and joint families differed in their familial and religious values at practice levels. Indian joint family system cultivates a set of peculiar collective values that may have more relevance for affirming the participants during the current pandemic. The individualistic values are based on conditional sources of power and status which may have involved different mechanism of affirmation while collectivistic values like compassion and service to others may be more conducive as they tend to be less conditional (Burson et al., 2012; Schimel et al., 2004). The Indian joint family system has been known for cultivating social relationships of unconditional and transcendental nature (I can't live without my family 
and community), it may facilitate more affirmation in collective values in their members in the face of the current threat (Burson et al., 2012; Crocker et al., 2008; Shnabel et al., 2013).

The participants from the nuclear families showed reliance on individual-focused values of selfreliance, self-compassion whereas those who valued joint family reflected upon the significance of cooperation, interdependence, and compassion. Thus, affirming in the relevant values, beliefs and roles as well engaging themselves with the appropriate activities (spending time with their family members engaging in religious practices etc.) might have helped them to affirm in their desirable values. This affirmation in the relevant values or actions helped them to cope up with the threat created by COVID-19. As the threat was serious and unavoidable, the activation of self-affirmation in familial and religious values was natural. Major religious values which were observed in the reporting of the participants were love, gratitude, goodness, humanism, sacrifice, self-control, commitment and transcendence. It has been suggested that self-affirmation primarily occurs when the threat belongs to an important area of individuals (D. K. Sherman \& Cohen, 2006; David K. Sherman et al., 2000).

Some previous researchers have argued that engaging in an activity promotes specific values, beliefs and roles pertinent to the identity of individuals and facilitate self-integrity and worth $(\mathrm{G}$. L. Cohen $\&$ Sherman, 2007). The affirmation in the most desirable values of individuals broadens their perception about their identity to a larger perspective that in turn, shifts attention from the current threat and reduced their use of defences and act more effectively (D. K. Sherman \& Cohen, 2006). It has been argued that self-affirmation may get activated either through reflecting up relevant roles, values and beliefs or engaging in positive activities. Many mechanisms have been proposed to explain the positive effects of self-affirmation. It has been suggested that self-affirmation acts as a buffer against stress by changing the psychological and physiological processes (G. L. Cohen \& Sherman, 2014; J. D. Creswell et al., 2005; J. David Creswell et al., 2013). Another view says that self-affirmation reduces defensiveness and thus, makes available more psychological resources to deal with the threat (D. K. Sherman \& Cohen, 2006).

The affirmation in values inherent in especially joint family and traditional religious practices to face the current threat may be significant as self-affirmation has been suggested to cultivate positive mood (Ferrer et al., 2012), collective self-esteem (Armitage, 2012; G. L. Cohen et al., 2000; Jaremka et al., 2011), cognitive processing, other-directed feeling and connectedness with others (Burson et al., 2012; Wakslak \& Trope, 2009). The participants belonging to the nuclear families and believed in practising evident components of religion showed affirmation in values confined to their personal experiences and outcomes. Thus, the individuals carrying individualistic and collectivistic values exhibited dissimilar preferences in their values. It may be due to the fact the two groups may have perceived different benefits of belonging to the two values and showed different mechanisms of self-affirmation (D. K. Sherman \& Cohen, 2006). The collectivists affirm easily regarding family, interdependence and religion whereas individuals having individualistic-orientation show preferences for values relevant for their personal self (Heine \& Lehman, 1997; Hoshino-Browne et al., 2004). The coexistence of individualism and collectivism in India may be possible due to its situation in the transition period. This coexistence of the two cultural value systems may be argued to be working behind the simultaneous presence of independent and interdependent self-affirmations as has been suggested by earlier researchers (Pandey et al., 2019; Sinha \& Tripathi, 1994). This study is one of the limited studies which simultaneously showed an initial clue of the coexistence and functioning of independent and interdependent self-affirmation. More studies are needed to verify their dynamics and relationships with the various life

outcomes of people. The findings may have theoretical, practical and policy implications especially for developing societies to understand intergenerational and intergroup relationships and outcomes.

\section{References}

Alexander, K. M. (2014). Self-affirmation: A regulatory fit analysis [University of Pittsburgh ETD]. University of Pittsburgh. http://d-scholarship.pitt.edu/20908/ 
Armitage, C. J. (2012). Evidence that self-affirmation reduces body dissatisfaction by basing self-esteem on domains other than body weight and shape: Self-affirmation and body satisfaction. Journal of Child Psychology and Psychiatry, 53(1), 81-88. https://doi.org/10.1111/j.1469-7610.2011.02442.x

Barbour, R. S. (2001). Checklists for improving rigour in qualitative research: A case of the tail wagging the dog? BMJ, 322(7294), 1115-1117. https://doi.org/10.1136/bmj.322.7294.1115

Binning, K. R., Sherman, D. K., Cohen, G. L., \& Heitland, K. (2010). Seeing the Other Side: Reducing Political Partisanship via Self-Affirmation in the 2008 Presidential Election: Seeing the Other Side. Analyses of Social Issues and Public Policy, 10(1), 276-292. https://doi.org/10.1111/j.1530-2415.2010.01210.x

Bormann, J. E., Thorp, S. R., Wetherell, J. L., Golshan, S., \& Lang, A. J. (2013). Meditation-based mantram intervention for veterans with posttraumatic stress disorder: A randomized trial. Psychological Trauma: Theory, Research, Practice, and Policy, 5(3), 259-267. https://doi.org/10.1037/a0027522

Brooks, S. K., Webster, R. K., Smith, L. E., Woodland, L., Wessely, S., Greenberg, N., \& Rubin, G. J. (2020). The psychological impact of quarantine and how to reduce it: Rapid review of the evidence. The Lancet, 395(10227), 912-920. https://doi.org/10.1016/S0140-6736(20)30460-8

Burson, A., Crocker, J., \& Mischkowski, D. (2012). Two Types of Value-Affirmation: Implications for Self-Control Following Social Exclusion. Social Psychological and Personality Science, 3(4), 510-516. https://doi.org/10.1177/1948550611427773

Cai, H., Sedikides, C., \& Jiang, L. (2013). Familial Self as a Potent Source of Affirmation: Evidence From China. Social Psychological and Personality Science, 4(5), 529-537. https://doi.org/10.1177/1948550612469039

Centers for Disease Control and Prevention. (2020, April 27). Coronavirus Disease 2019 (COVID19) - Symptoms. Centers for Disease Control and Prevention. https://www.cdc.gov/coronavirus/2019ncov/symptoms-testing/symptoms.html

Cheadle, A. C. D., \& Dunkel Schetter, C. (2017). Untangling the mechanisms underlying the links between religiousness, spirituality, and better health. Social and Personality Psychology Compass, 11(2), e12299. https://doi.org/10.1111/spc3.12299

Cohen, G. L., Aronson, J., \& Steele, C. M. (2000). When Beliefs Yield to Evidence: Reducing Biased Evaluation by Affirming the Self. Personality and Social Psychology Bulletin, 26(9), 1151-1164. https://doi.org/10.1177/01461672002611011

Cohen, G. L., \& Sherman, D. K. (2007). Self-affirmation theory. In R. Baumeister \& K. Vohs, Encyclopedia of Social Psychology (pp. 787-789). SAGE Publications.

Cohen, G. L., \& Sherman, D. K. (2014). The Psychology of Change: Self-Affirmation and Social Psychological Intervention. Annual Review of Psychology, 65(1), 333-371. https://doi.org/10.1146/annurev-psych010213-115137

Cohen, Geoffrey L., Sherman, D. K., Bastardi, A., Hsu, L., McGoey, M., \& Ross, L. (2007). Bridging the partisan divide: Self-affirmation reduces ideological closed-mindedness and inflexibility in negotiation. Journal of Personality and Social Psychology, 93(3), 415-430. https://doi.org/10.1037/0022-3514.93.3.415

Creswell, J. D., Welch, W. T., Taylor, S. E., Sherman, D. K., Gruenewald, T. L., \& Mann, T. (2005). Affirmation of Personal Values Buffers Neuroendocrine and Psychological Stress Responses. Psychological Science, 16(11), 846-851. https://doi.org/10.1111/j.1467-9280.2005.01624.x

Creswell, J. David, Dutcher, J. M., Klein, W. M. P., Harris, P. R., \& Levine, J. M. (2013). Self-Affirmation Improves Problem-Solving under Stress. PLoS ONE, 8(5), e62593. https://doi.org/10.1371/journal.pone.0062593 
Creswell, J. W. (2004). Designing A Mixed Methods Study In Primary Care. The Annals of Family Medicine, 2(1), 7-12. https://doi.org/10.1370/afm.104

Creswell, J. W. (2014). Research design: Qualitative, quantitative, and mixed methods approaches (4th ed). SAGE Publications.

Crocker, J., Niiya, Y., \& Mischkowski, D. (2008). Why Does Writing About Important Values Reduce Defensiveness?: Self-Affirmation and the Role of Positive Other-Directed Feelings. Psychological Science, 19(7), 740-747. https://doi.org/10.1111/j.1467-9280.2008.02150.x

Ferrer, R. A., Shmueli, D., Bergman, H. E., Harris, P. R., \& Klein, W. M. P. (2012). Effects of SelfAffirmation on Implementation Intentions and the Moderating Role of Affect. Social Psychological and Personality Science, 3(3), 300-307. https://doi.org/10.1177/1948550611419265

Gaines, S. O., Marelich, W. D., Bledsoe, K. L., Steers, W. N., Henderson, M. C., Granrose, C. S., Barájas, L., Hicks, D., Lyde, M., Takahashi, Y., Yum, N., Ríos, D. I., García, B. F., Farris, K. R., \& Page, M. S. (1997). Links between race/ethnicity and cultural values as mediated by racial/ethnic identity and moderated by gender. Journal of Personality and Social Psychology, 72(6), 1460-1476. https://doi.org/10.1037/00223514.72.6.1460

Guest, G., Bunce, A., \& Johnson, L. (2006). How Many Interviews Are Enough?: An Experiment with Data Saturation and Variability. Field Methods, 18(1), 59-82. https://doi.org/10.1177/1525822X05279903

Guest, G., MacQueen, K. M., \& Namey, E. E. (2012). Applied thematic analysis. Sage Publications.

Harris, K. A., Howell, D. S., \& Spurgeon, D. W. (2018). Faith concepts in psychology: Three 30-year definitional content analyses. Psychology of Religion and Spirituality, 10(1), 1-29. https://doi.org/10.1037/rel0000134

Heine, S. J., \& Lehman, D. R. (1997). Culture, Dissonance, and Self-Affirmation. Personality and Social Psychology Bulletin, 23(4), 389-400. https://doi.org/10.1177/0146167297234005

Helms, J. E., \& Cook, D. A. (1999). Using race and culture in counseling and psychotherapy: Theory and process. Allyn and Bacon.

History.com Editors. (2019, September). Hinduism. HISTORY. https://www.history.com/topics/religion/hinduism

Hoshino-Browne, E., Zanna, A. S., Spencer, S. J., \& Zanna, M. P. (2004). Investigating attitudes crossculturally: A case of cognitive dissonance among East Asians and North Americans. In G. Haddock \& G. R. Maio, Contemporary perspectives on the psychology of attitudes (pp. 375-397). Psychology Press.

Hoshino-Browne, E., Zanna, A. S., Spencer, S. J., Zanna, M. P., Kitayama, S., \& Lackenbauer, S. (2005). On the cultural guises of cognitive dissonance: The case of Easterners and Westerners. Journal of Personality and Social Psychology, 89(3), 294-310. https://doi.org/10.1037/0022-3514.89.3.294

Iwamoto, D. K., \& Liu, W. M. (2010). The impact of racial identity, ethnic identity, Asian values, and race-related stress on Asian Americans and Asian international college students' psychological well-being. Journal of Counseling Psychology, 57(1), 79-91. https://doi.org/10.1037/a0017393

Jaremka, L. M., Bunyan, D. P., Collins, N. L., \& Sherman, D. K. (2011). Reducing defensive distancing: Selfaffirmation and risk regulation in response to relationship threats. Journal of Experimental Social Psychology, 47(1), 264-268. https://doi.org/10.1016/j.jesp.2010.08.015

Jiao, W. Y., Wang, L. N., Liu, J., Fang, S. F., Jiao, F. Y., Pettoello-Mantovani, M., \& Somekh, E. (2020). Behavioral and Emotional Disorders in Children during the COVID-19 Epidemic. The Journal of Pediatrics, S002234762030336X. https://doi.org/10.1016/j.jpeds.2020.03.013

Kemppainen, J., Bormann, J. E., Shively, M., Kelly, A., Becker, S., Bone, P., Belding, W., \& Gifford, A. L. (2012). Living with HIV: Responses to a Mantram Intervention Using the Critical Inci- 
dent Research Method. The Journal of Alternative and Complementary Medicine, 18(1), 76-82. https://doi.org/10.1089/acm.2009.0489

Kim, B. S. K., Atkinson, D. R., \& Yang, P. H. (1999). The Asian Values Scale: Development, factor analysis, validation, and reliability. Journal of Counseling Psychology, 46(3), 342-352. https://doi.org/10.1037/00220167.46.3.342

Kim, B. S. K., \& Omizo, M. M. (2005). Asian and European American Cultural Values, Collective SelfEsteem, Acculturative Stress, Cognitive Flexibility, and General Self-Efficacy Among Asian American College Students. Journal of Counseling Psychology, 52(3), 412-419. https://doi.org/10.1037/0022-0167.52.3.412

Markus, H. R., \& Kitayama, S. (1991). Culture and the self: Implications for cognition, emotion, and motivation. Psychological Review, 98(2), 224-253. https://doi.org/10.1037/0033-295X.98.2.224

Pandey, R., Tiwari, G. K., Parihar, P., \& Rai, P. K. (2019). Positive, not negative, self-compassion mediates the relationship between self-esteem and well-being. Psychology and Psychotherapy: Theory, Research and Practice. https://doi.org/10.1111/papt.12259

Pettit, N. C., \& Lount, R. B. (2010). Looking down and ramping up: The impact of status differences on effort in intergroup contexts. Journal of Experimental Social Psychology, 46(1), 9-20. https://doi.org/10.1016/j.jesp.2009.08.008

Saunders, B., Sim, J., Kingstone, T., Baker, S., Waterfield, J., Bartlam, B., Burroughs, H., \& Jinks, C. (2018). Saturation in qualitative research: Exploring its conceptualization and operationalization. Quality ES Quantity, 52(4), 1893-1907. https://doi.org/10.1007/s11135-017-0574-8

Scabini, E., \& Manzi, C. (2010). Identity in family processes. In S. J. Schwartz, K. Luyckx, \& V. L. Vignoles, Handbook of identity theory and research (pp. 565-584). Springer.

Schimel, J., Arndt, J., Banko, K. M., \& Cook, A. (2004). Not All Self-affirmations Were Created Equal: The Cognitive and Social Benefits of Affirming The Intrinsic (vs. Extrinsic) Self. Social Cognition, 22(1), 75-99. https://doi.org/10.1521/soco.22.1.75.30984

Sherman, D. K., \& Cohen, G. L. (2006). The psychology of self-defense: Self-affirmation theory. In M. P. Zanna, Advances in experimental social psychology (Vol. 38, pp. 183-242). Guildford Press.

Sherman, David K., \& Cohen, G. L. (2006). The Psychology of Self-defense: Self-Affirmation Theory. In $A d-$ vances in Experimental Social Psychology (Vol. 38, pp. 183-242). Elsevier. https://doi.org/10.1016/S00652601(06)38004-5

Sherman, David K., \& Kim, H. S. (2005). Is There an "I" in "Team"? The Role of the Self in Group-Serving Judgments. Journal of Personality and Social Psychology, 88(1), 108-120. https://doi.org/10.1037/00223514.88.1.108

Sherman, David K., Nelson, L. D., \& Steele, C. M. (2000). Do Messages about Health Risks Threaten the Self? Increasing the Acceptance of Threatening Health Messages Via Self-Affirmation. Personality and Social Psychology Bulletin, 26(9), 1046-1058. https://doi.org/10.1177/01461672002611003

Shnabel, N., Purdie-Vaughns, V., Cook, J. E., Garcia, J., \& Cohen, G. L. (2013). Demystifying ValuesAffirmation Interventions: Writing About Social Belonging Is a Key to Buffering Against Identity Threat. Personality and Social Psychology Bulletin, 39(5), 663-676. https://doi.org/10.1177/0146167213480816

Sinha, D., \& Tripathi, R. C. (1994). Individualism in a collectivist culture: A case of coexistence of opposites. In U. Kim, H. C. Triandis, C. Kağitçibaşi, S. C. Choi, $\mathscr{G}$ G. Yoon (Eds.), Cross-cultural research and methodology series, Vol. 18. Individualism and collectivism: Theory, method, and applications (pp. 123136). Sage Publications.

Smith, D. (2019). Using Scripture as Affirmations to Promote Positive Religious Coping, Secure Attachment, and Posttraumatic Growth in Christian Clients in Psychotherapy- 
ProQuest. $\quad$ https://search.proquest.com/openview/c5cc6c51c61d4a10c01f0b2de23d3d9d/1.pdf?pqorigsite $=$ gscholar $\&$ cbl $=18750 \&$ diss $=\mathrm{y}$

Steele, C. M. (1988). The psychology of self-affirmation: Sustaining the integrity of the self. In Berkowitz L. (Ed.). Advances in experimental social psychology (pp. 261-302). Academic Press.

Strong, P. (1990). Epidemic psychology: A model. Sociology of Health and Illness, 12(3), 249-259. https://doi.org/10.1111/1467-9566.ep11347150

Tiwari, G. K., Kashyap, A. K., Rai, P. K., Tiwari, R. P., \& Pandey, R. (2020). The Collective-affirmation in Action: Understanding the Success of Lockdown in India after the Outbreak of COVID-19 [Preprint]. Preprints. https://doi.org/10.22541/au.158949202.27402247

United Nations Organization. (2020). Policy Brief: The Impact of COVID-19 on children (pp. 1-17).

Wakslak, C. J., \& Trope, Y. (2009). Cognitive consequences of affirming the self: The relationship between self-affirmation and object construal. Journal of Experimental Social Psychology, 45(4), 927-932. https://doi.org/10.1016/j.jesp.2009.05.002

Weber, J., \& Goldmeier, D. (1983). Medicine and the Media. British Medical Journal, 287(6389), 420-420. https://doi.org/10.1136/bmj.287.6389.420

World Health Organization. (2020a). Coronavirus. https://www.who.int/westernpacific/healthtopics/coronavirus

World Health Organization. (2020). Coronavirus disease 2019 (COVID-19) Situation Report111. https://www.who.int/docs/default-source/coronaviruse/situation-reports/20200429-sitrep-100-covid19.pdf?sfvrsn=bbfbf3d1_6 